\title{
ASSIMETRIA INFORMACIONAL E EFICIÊNCIA SEMIFORTE DO MERCADO
}

\section{RESUMO}

0 artigo investiga a assimetria informacional no mercado de capitais brasileiro quando da convocação para a Assembléia Geral O rdinária (AGO) ou para a Reunião do Conselho de Administração (RCA), desde que na pauta conste a intenção de aumentar o capital, via subscrição de ações, ou quando do anúncio da decisão de aumentar o capital, verificando-se a eficiência semiforte do mercado e a assimetria informacional. Os dados foram obtidos da Comissão de Valores Mobiliários (CVM) e do banco de dados da empresa de consultoria Lafis. Com base em pesquisa teórica e empírica, investiga-se a existência de retornos anormais quando do anúncio de novas subscrições, bem como de retornos anormais acumulados para um período anterior (-20 dias) e um período posterior (+20 dias) em relação à data do anúncio. Os resultados da pesquisa sugerem a existência de assimetria informacional no mercado de capitais brasileiro e a inexistência da eficiência semiforte do mercado.

\section{Neuza Maria Belo}

Faculdades Pedro Leopoldo, FGV-RJ e Faculdade Pitágoras

\section{Haroldo Guimarães Brasil}

Faculdades Pedro Leopoldo e IBMEC-MG

ABSTRACT This study aimed to investigate the informational asymmetry in the Brazilian Stock Market, either upon calls for Ordinary General Assemblies or Board M eetings intended to increase capital through underwritings, or upon announcements communicating the decision of capital increase. Therefore, the semi-strong efficiency and the informational asymmetry of the market were verified. The data were obtained through the Stock Exchange and the database of the consulting firm, Lafis. Based on theoretical and empirical research, it investigated the existence of abnormal returns upon the announcement of new underwritings, and also the existence of abnormal returns accumulated for a previous period ( -20 days) and a later period ( +20 days), in relation to the date of the announcement. The results of the research suggest not only the existence of informational asymmetry in the Brazilian Stock Market but also the absence of semi-strong efficiency in the market.

PALAVRAS-CHAVE Assimetria informacional, eficiência semiforte, estudo de evento, subscrição, ações. KEYWORDS Informational asymmetry, semi-strong efficiency, event study, underwriting, actions. 


\section{INTRODUÇÃO}

A seleção de alternativas de investimentos deve vir precedida de uma análise criteriosa. As especulações sobre as informações que comunicam novas emissões, transmitidas pelas empresas subscritoras, devem ser objeto de análise, pois podem influenciar os preços das ações. A partir desse pressuposto, a questão que se coloca é: as informações que comunicam novas emissões, transmitidas pelas empresas subscritoras, influem nos preços das ações?

0 objetivo geral deste estudo é investigar a ocorrência de retornos anormais nos preços das ações quando do anúncio de novas subscrições, verifican do a existência de assimetria informacional no mercado de capitais brasileiro e a eficiência semiforte do mercado.

Como decorrência do objetivo geral, busca-se ainda: (a) verificar a existência de retornos anormais negativos quando do anúncio da emissão, à luz dos estudos empíricos previamente realizados; (b) verificar a existência de retornos anormais no período de 20 dias úteis anteriores ao anúncio, identificando a ocorrência de insider information; (c) verificar se há retornos anormais no período de 20 dias úteis posteriores ao anúncio, identificando o tempo de ajuste do mercado a novas informações.

Atualmente, uma das preocupações das empresas diz respeito ao seu equilíbrio financeiro e à sua estabilidade no mercado. Com a oscilação da economia, as empresas necessitam de cuidadoso planejamento financeiro, no qual a avaliação das alternativas de financiamento assume papel crucial para a maximização da riqueza, exigindo o enfoque máximo de seus administradores na busca de fontes menos onerosas. Desse modo, a verificação de impactos no preço das ações das empresas que pretendem obter novos financiamentos via subscrição de novas ações assume importância crítica no processo de financiamento das organizações brasileiras.

Adicionalmente, 0 artigo aborda alguns aspectos que podem ser determinantes para a avaliação das reações negativas do mercado diante dos sinais transmitidos pelas empresas quando estas efetuam novas emissões de ações.

\section{REFERENCIAL TEÓRICO}

\section{Eficiência informacional dos mercados}

0 mercado eficiente é definido por Fama (1973, p. 133) como sendo aquele em que "os preços de seus títulos refletem integralmente todas as informações disponíveis naquele momento". A partir do ponto em que todas as informações estão refletidas no preço, os investidores sempre podem esperar obter uma taxa de retorno normal, eliminando, assim, a possibilidade de obtenção de ganhos anormais.

Roberts (1967) e Fama $(1970,1991)$ sistematizaram a teoria de mercados eficientes, a qual afirma que as informações rel evantes são incorporadas, de forma imediata e correta, aos preços dos ativos financeiros, e que a melhor estimativa para o preço de um título é seu preço atual. Assim, a eficiência do mercado é que estabelece o preço justo, pois todas as informações relevantes estão refletidas no valor estipulado. Para que a hipótese de eficiência do mercado seja val idada, al gumas condições são necessárias. Para Fama (1970, p. 387), "as informações estão disponíveis a todos; não há custos de transação na negociação; todos os investidores possuem expectativas homogêneas, isto é, todos têm a mesma distribuição de probabilidade $\mathrm{e}^{1}$ dos retornos dos ativos".

Para Damodaran (2002) al guns conceitos importantes estão implícitos na definição de mercados eficientes, quais sejam: os erros no preço não podem ser tendenciosos, ou seja, podem ser maiores ou menores do que o valor real, desde que esses desvios sejam al eatórios; ${ }^{2}$ os desvios aleatórios do valor real não podem ser correlacionáveis com qualquer variável observada; como os desvios são aleatórios, nenhum investidor deve ser capaz de, consistentemente, encontrar ações supervalorizadas utilizando quaisquer estratégias de investimento.

Formas de eficiência do mercado

As formas de eficiência do mercado foram definidas por Roberts (1967) e Fama (1970) como weak form, ou forma fraca; semi-strong form, ou forma semiforte; e strong form, ou forma forte. ${ }^{3}$

Para Fama (1970), na forma fraca de eficiência os retornos esperados são formados pelo conjunto de informações disponíveis, que se encontram refletidas nos preços. Assim, exclui-se a possibilidade da existência de estratégias de negociação fundamentadas em informações passadas capazes de promover ganhos ou retornos que excedam os de equilíbrio, ou seja, informações contidas nos preços (ou retornos) passados não são úteis para a obtenção de retornos extraordinários.

Segundo Ross, Westerfield e Jaffe (1995, p. 266), "a eficiência na forma fraca éo tipo menos exigente de eficiência que podemos esperar de um mercado financeiro, pois a informação histórica sobre preços éa espécie mais fácil de informação que se pode adquirir a respeito de uma ação". Para os autores, se fosse possível obter lucros relevantes simplesmente verificando padrões de comportamento nas 
séries de preços de ações, todos o fariam, e qual quer lucro logo desapareceria na luta para obtê-los.

De acordo com Fama (1970), na forma semiforte de eficiência as informações publicamente disponíveis já precisam estar refletidas no preço da ação. Assim sendo, os preços não refletem apenas o histórico passado, como também todas as informações disponíveis publicamente. Desse modo, nenhum investidor pode obter retornos anormais baseados em informações publicamente disponíveis, visto que os preços se ajustam rapidamente à divul gação de novas informações.

French e Roll (1986) esclarecem que informações públicas são aquelas que se tornam conhecidas ao mesmo tempo em que afetam os preços. É preciso lembrar que a reação do mercado a novas informações precisa ser instantânea e não ten denciosa. Segundo Damodaran (2002), as possíveis reações do mercado diante de novas informações são as seguintes: imediata confirmação da hipótese de eficiência semiforte; lentos retornos adicionais aos investidores após o anúncio; e exagerada reação instantânea com correção posterior.

Brigham, Gapenshi e Ehrhardt (2001) ressaltam outra implicação da eficiência semiforte do mercado: a informação divulgada somente terá influência no preço caso seja diferente das expectativas do mercado. Em complemento, Perobelli e N ess J r. (2000) acrescentam que apenas informações de livre acesso, inéditas e não antecipadas, devem exercer algum impacto no preço futuro da ação. Já Elton e Gruber (1995) evidenciam que podem ser necessários diversos dias para que os investidores sejam capazes de analisar total mente o impacto dessas informações e, conseqü entemente, da transformação na condição da empresa. 0 que deve haver depois do anúncio éuma estimativa não enviesada do equilíbrio e uma aval iação do impacto nos lucros pelos investidores.

Nesse sentido, Fama (1965) esclarece que grandes mudanças obtidas por meio de informações são seguidas por grandes mudanças nos preços (de sinal al eatório), enquanto pequenas mudanças provocadas pela informação tendem a ser seguidas por pequenas mudanças nos preços. Para analisar a forma semiforte, Ross, Westerfield e Jaffe (1995) apresentam dois tipos de testes: estudo de evento e desempenho de fundos mútuos. Para al guns autores, como Elton e Gruber (1995) e Damodaran (2002), o desempenho de fundos mútuos deve ser aplicado no teste da eficiência forte. Em um estudo de evento, "os retornos em torno de um evento são esquadrinhados à procura de evidência de retornos adicionais" (Damodaran, 2002, p. 190). Busca-se, então, mensurar a velocidade de ajuste dos preços ao redor de uma data específica (a data de divulgação da informação).
N a forma forte de eficiência, o mercado é eficiente quando os preços dos títulos refletem as informações privadas e não privadas, não existindo para o investidor nenhum ganho anormal em relação ao mercado, pois os preços se ajustam imediatamente ao surgimento de novas informações. Assim, um insider, de posse de informações privadas, não obteria nenhum ganho adicional. Para verificar a eficiência forte, são real izados estudos com investidores que possuem acesso a informações privadas: fundos de pensão e seus administradores.

De acordo com Fama (1991), esses testes determinam a avaliação do acesso de investidores a informações privadas, mensurando os retornos anormais em mais de um período de tempo. A verificação da forma forte, segundo Ross, Westerfield e Jaffe (1995), pode ser feita mediante a análise de operações realizadas por insiders.

Para Elton eGruber (1995), essa análise deverá ser feita mediante 0 desempenho dos fundos mútuos. Ressaltam, ainda, que a maioria dos estudos de fundos mútuos que avaliam a forma forte padece do viés de sobrevivência, ou seja, habitualmente são excluídos os fundos que já encerraram suas atividades, os mesmos que apresentam desempenho abaixo da média.

\section{Assimetria informacional}

\section{Aspectos conceituais}

Assimetria informacional é a descrição de um fenômeno segundo o qual al guns agentes econômi cos têm mais informações do que outros. Para exemplificar, seja mencionado o caso de um tomador de um empréstimo, o qual conhece sua própria capacidade de pagamento muito melhor do que aquel es que emprestam.

As implicações da assimetria informacional foram inicialmente analisadas por Akerl of (1970). Ele ilustra esse fenômeno citando como exemplo o mercado de carros usados, num estudo sobre lemon markets, como são conhecidos os carros vel hos e ruins nos EUA. ${ }^{4}$ Q uem vende um automóvel tem pleno conhecimento das condições de seu veículo, mas quem compra desconhece essas condições. Em função dessa assimetria de informações, o comprador já vai disposto a pagar um preço mais baixo pelo veículo. Em conseqüência, quem tem um carro bom não quer vender, pois vai receber aquém do valor real do seu veículo. Assim, sobram no mercado produtos de baixa qualidade, o que el eva a desconfiança dos compradores.

Quando existe assimetria informacional, tendem a ocorrer conflitos de interesse. Podem ser reconhecidos dois tipos de problemas advindos da assimetria de informações: (a) sel eção adversa - ocorre quando um lado 
do mercado não pode observar o tipo ou a qualidade dos bens e serviços colocados à disposição no outro (lado); (b) risco moral - ocorre quando um lado do mercado não pode observar a ação do outro.

\section{Assimetria informacional e mercado eficiente}

Um mercado é eficiente quando as informações não são assimétricas, ou seja, quando os investidores têm informações suficientes para tomar suas decisões, o que resulta em uma correta precificação dos ativos. Em contrapartida, a insuficiência de informações resultará na precificação incorreta ou na demora para ajustes nos preços.

M yers e M ajluf (1984) analisaram decisões de investimentos financiadas via emissão de novas ações, quando os gerentes têm informações privil egiadas que os investidores não possuem, e partindo do pressuposto de que os administradores agem no interesse dos atuais acionistas. ${ }^{5}$ Os autores ressaltaram situações em que a emissão de novas ações para financiar projetos com valor presente líquido (VPL) positivo não era desejável. Assim, demonstraram que, quando as ações da empresa estão subavaliadas pelo mercado, o valor da diluição ocasionada pela nova emissão poderá ser maior do que os ganhos obtidos com os projetos de VPL positivo.

Por outro Iado, a utilização de emissão de ações para financiamentos de projetos pode sinalizar uma superavaliação das ações, que gera um problema de seleção adversa, pois os investidores podem inferir que, se a empresa precisa de recursos, este é um indicador de que seus fluxos de caixa futuros não são bons, isto é, as ações estão superavaliadas. Dessa forma, os administradores evitarão a emissão de ações para financiar projetos que necessitem de capital próprio, pois os anúncios de emissão podem resultar em um impacto negativo no preço da ação, explicando, assim, retornos an ormais negativos. Portanto, a decisão correta de investir em projetos com VPL positivo mas que necessitem de capital via emissão pode ser pior para os acionistas do que a rejeição do projeto.

Para os autores citados, seguindo uma conduta racional, os dirigentes de uma empresa somente lançam ações quando percebem que o preço corrente de mercado está supervalorizado enão lançam ações se, em sua avaliação, o preço está subavaliado. ${ }^{6}$ Assim, os novos acionistas somente adquirem ações a preços superaval iados. Mas, como a percepção do mercado é idêntica, as novas colocações de ações somente terão sucesso se feitas a preços que imponham diluição de valor para os controladores.

N esse sentido, algumas pesquisas têm comprovado 0 trabal ho de Myers e M ajluf (1984), como o de Greenwald, Stiglitz eWeiss (1984), e o de Fazzari, Hubbard e Peterson
(1988) (ambos citados por Garcia, 2002), para os quais os novos acionistas exigem um prêmio ao comprar ações de empresas de bom nível para compensar as perdas provenientes do mercado de limões. No Brasil, "a tradução mais adequada seria abacaxi. Em decorrência, o prêmio exigido eleva o custo das ações emitidas acima do custo de oportunidade total da empresa" (Garcia, 2002, p. 8).

Outro ponto importantenos trabal hos de Myers (1984) e Myers e Majluf (1984) é a assimetria na posse de informações por parte dos administradores, com relação ao mercado, especialmente em relação aos potenciais acionistas, que vai contra eventuais interesses da empresa para obter recursos, objetivando financiar projetos de VPL positivo. A solução para tal fato seria a busca, pelos administradores, da redução ou eliminação dessa percepção assimétrica, revelando, tanto quanto possível, as perspectivas futuras da empresa.

Hertzel et al. (2002) estudaram o desempenho das emissões privadas depois do anúncio de emissões. Embora tenham encontrado um desempenho positivo quando do anúncio, verificaram também que, ao longo de três anos, essas empresas apresentaram desempenho inferior a vários benchmarks.

No Brasil, Garcia (2002) parte do seguinte pressuposto:

No caso da empresa decidir-se pelo lançamento de ações para o aumento de capital (oferta primária que não seja lançamento público inicial) e ainda possuindo capacidade de crédito, essa companhia não espera um bom fluxo de benefícios futuros, ou seja, os próprios atuais controladores não vêem boas perspectivas futuras para 0 fluxo de caixa da empresa. Assim, o mercado enxerga no lançamento de ações para aumento de capital um sinal negativo e admite a hipótese de seleção adversa, na qual um agente deseja vender algo por um certo preço porque os potenciais compradores somente admitem pagar um valor inferior. N esse quadro, o evento do lançamento primário de ações seria percebido pelo mercado com forte conteúdo de informações negativas. Temos, portanto, que o anúncio da decisão de emissão de ações deve provocar a perda de val or das ações detidas pelos atuais acionistas. (GARCIA, 2002, p. 10-11).

Este artigo inicia sua investigação considerando os seguintes pressupostos, baseados na fundamentação teórica: a) os administradores agem no interesse dos atuais acionistas; b) as empresas somente emitem novas ações se acreditarem que o preço das mesmas está supervalorizado; c) a emissão de novas ações é caracterizada por um sinal negativo ao mercado. 


\section{PROCEDIMENTOS METODOLÓGICOS}

\section{Definição do evento}

0 evento considerado neste estudo foi o anúncio de subscrição ou convocação para a Assembléia Geral Ordinária ( $A G O$ ) ou, ainda, de Reunião do Conselho de Administração (RCO), desde que constasse a intenção de aumentar o capital via emissão de ações. Os dados relativos aos anúncios em questão foram retirados do banco de dados da Consultoria Lafis.7 Todas as empresas analisadas efetuaram subscrições primárias não iniciais no período compreendido entre $1^{\circ}$ de julho de 1995 e 30 de abril de 2005.

\section{Definição do período do evento}

Q uanto ao período do evento considerado, ou janela de evento para a análise do retorno, o intervalo foi de 41 dias, similar ao de pesquisas já realizadas com empresas brasileiras, como o trabalho de Bertucci, Amaral e Garcia (2002), que utilizaram uma janela de evento com o mesmo intervalo. 0 período compreendido entre (-) $20 \mathrm{~d}$ e (-) 1d permitirá a identificação do vazamento de informações privilegiadas anteriormenteà sua divul gação oficial pela empresa emissora; e o período compreendido entre $(+) 1 \mathrm{~d}$ e $(+) 20 \mathrm{~d}$ mostrará a reação posterior do mercado à divulgação das informações (sinal) e, conseqüentemente, a velocidade e precisão dos ajustes dos preços em relação às novas informações liberadas ao mercado. 0 dia 0 d será o período de análise, que permitirá mensurar os efeitos da divulgação de informações (sinais) nos preços das ações.

\section{Determinação do critério de seleção}

A população deste estudo compreen de todas as empresas brasileiras que efetuaram subscrições primárias não iniciais no período compreendido entre 1ำ de jul ho de 1995 e 30 de abril de 2005. A amostra foi definida a partir de dois critérios: primeiramente, foram selecionadas as empresas que efetuaram subscrições públicas não iniciais no período compreendido entre $1^{\circ}$ de julho de 1995 e 30 de abril de 2005, dados esses que foram obtidos por meio dos relatórios da Comissão de Valores M obiliários (CVM).

Após o levantamento das empresas, foram excluídas aquelas que não apresentavam anúncios, informando subscrições ou convocação para AGO ou RCA, nos quais constasse explicitamente que um dos itens em pauta seria o aumento de capital. Além disso, para que a empresa não fosse excluída da amostra, era necessário que ela houvesse divulgado ao mercado, de forma antecipada, a intenção de efetuar um aumento de capital.
Assim, comunicações de deliberações em AGO ou RCA não foram consideradas, pois foram interpretadas como informação já divulgada. É importante evidenciar que o cuidado na sel eção da amostra não garante que a informação publicada seja a que deu conhecimento ao mercado sobre o evento. Para a exclusão, efetuou-se um levantamento no banco de dados da Consultoria Lafis, pesquisando-se, individualmente, em cada empresa, as notícias divulgadas por intermédio de jornais de circulação nacional. É oportuno ressaltar que esse levantamento limitou-se à base de dados da Consultoria Lafis.

Uma restrição natural imposta na seleção de eventos foi a existência de dados bursáteis dos títulos das empresas emitentes no período de observação, compreendido entre 20 dias antes e 20 dias depois da data do anúncio.

Algumas empresas não tiveram negociações de seus papéis em determinados dias. Para estes, foram considerados, na análise, os valores da negociação do dia anterior. Entretanto, em alguns casos, o problema alcançou tal magnitude que os eventuais prejuízos pela inclusão poderiam comprometer a análise. Por esse motivo, tais casos foram eliminados da amostra.

\section{Amostra e coleta de dados}

Para a análise do retorno das ações, os dados utilizados em relação a esse retorno, bem como sobre a variação do Índice da Bolsa de Valores de São Paulo (I bovespa), são secundários e foram obtidos por intermédio do banco de dados da Consultoria Lafis. Com base nas cotações de fechamento diárias, ajustadas em reais, calculou-se o retorno das ações utilizadas. A periodicidade diária foi escolhida em função da possibilidade de se tirar vantagem de informações anteriores sobre o dia específico no qual o evento (sinal) ocorre.

A despeito da maior liquidez das ações preferenciais, foram utilizadas neste estudo tanto ações preferenciais como ordinárias, no mercado de capitais brasileiro, em função do número reduzido de subscrições feitas por empresas brasileiras. 0 universo total de eventos envolvendo subscrições públicas não primárias - no período de 10 de julho de 1995 a 30 de abril de 2005 - é de 107 emissões públicas primárias.

\section{Cálculo da medida do retorno}

Para avaliar o impacto do evento, deve-se utilizar uma medida do retorno normal. Para seu cál culo, mensura-se o retorno definido como anormal ex-post, menos o retorno definido como normal. Primeiramente, faz-se necessário calcular o retorno nominal, e, para tanto, foi utilizada a fórmula 1: 


$$
R_{i t}=\operatorname{Ln}\left(\frac{P_{i t}}{P_{i t-1}}\right)
$$

\section{Em que:}

$\mathrm{R}_{\mathrm{it}}=$ retorno nominal da ação i, no dia t;

$P_{\text {it }}=$ preço de fechamento da ação i, no dia t, ajustado a todos os sinais transmitidos no dia;

$P_{i t-1}=$ preço de fechamento da ação i, no dia t- 1 , ajustado a todos os sinais transmitidos no dia.

Para o retorno anormal, foi utilizado o modelo de retornos ajustados aos mercados, pelo qual se faz a comparação entre o retorno das ações de determinada empresa e um índice apropriado. Neste caso, a escolha foi o I bovespa. Qualquer diferença encontrada é considerada anormal. ${ }^{8}$ De acordo com Brown eWarner (1980), a despeito de sua simplicidade, este modelo apresenta desempenho similar aos model os mais sofisticados. ${ }^{9}$

$$
A R_{i t}=R_{i t}-R_{m t}
$$

\section{Em que:}

$A R_{\text {it }}=$ retorno anormal da ação i no dia t;

$\mathrm{R}_{\text {it }}=$ retorno nominal da ação i no dia t;

$\mathrm{R}_{\mathrm{mt}}=$ retorno observado do portfólio de mercado (Ibovespa) no mesmo período.

Para a realização dos testes das hipóteses, adotaram-se os seguintes procedimentos:

- Retorno da ação:

$$
R_{i t}=\operatorname{Ln}\left(\frac{P_{i t}}{P_{i t-1}}\right)
$$

Em que:

$R_{\text {it }}=$ retorno da ação i no dia t;

$P_{i t}=$ preço nominal de fechamento da ação i no dia t, em moeda corrente nacional;

$P_{i, t-1}=$ preço de fechamento da ação i, no dia t- 1 , ajustado a todos os sinais transmitidos no dia.

- $O$ cálculo do retorno anormal $\left(A R_{i t}\right)$ é dado por:

$$
A R_{i t}=R_{i t}-R_{m t}
$$

Em que:

$\mathrm{R}_{\text {it }}=$ retorno real da ação i no dia t;

$\mathrm{R}_{\mathrm{mt}}=$ retorno real do Ibovespa no período $\mathrm{t}$.
- Cálculo dos retornos anormais cumulativos $\left(C A R_{t_{1} t_{2}}\right)$, para cada ação, entre duas datas quaisquer $t_{1}$ e $t_{2}:{ }^{10}$

$$
C A R_{i t_{1}, t_{2}}=\sum_{t_{1}}^{t_{2}} A R_{i t}
$$

- Cál culo dos retornos anormais cumulativos $\left(C A R_{t_{1}, t_{2}}\right)$, para todas as ações, entre duas datas quaisquer $t_{1}$ et $_{2}$ :

$$
C A R_{t_{1}, t_{2}}=\sum_{t_{1}}^{t_{2}} \overline{A R}
$$

Seguindo a metodologia aplicada por Cormelato e Terra (2003), é possível estimar um retorno anormal ajustado médio $\left(\overline{A R}_{t}\right)$. Uma reação negativa dos preços comprovaria a existência de assimetria informacional no mercado. A média dos retornos anormais dos ativos individuais pode ser calculada a partir dos retornos anormais individuais, ou seja, o cálculo do retorno anormal ajustado médio $\left(\overline{A R}_{t}\right)$ :

$$
\overline{A R}_{t}=\frac{\sum_{t}^{N_{t}} A R_{t}}{N_{t}}
$$

Em que:

$\mathrm{N}_{\mathrm{t}}=$ número de retornos observados no dia $\mathrm{t}$.

Para a agregação dos retornos anormais de cada ativo i para $\mathrm{N}$ eventos, o cálculo do retorno anormal médio cumulativo $\left(\overline{C A R}_{t_{1}, t_{2}}\right)$ é dado por:

$$
\overline{C A R}{ }_{t=t_{1}, t_{2}}=\frac{\sum_{i=1}^{N} A R_{t}}{N_{t}}
$$

Dessa forma, utilizando-se as fórmulas 5, 6, 7 e 8, e 9, 10 (apresentadas à frente), serão gerados os dados para o teste das hipóteses.

A hipótese de eficiência do mercado quanto a não ser possível obter ganhos anormais por parte de investidores que eventualmente disponham de informações confidenciais de empresas com as quais obtêm ganhos ilegítimos e ilegais será comprovada pela existência de retornos anormais ao longo do período entre os dias $(-20)$ e $(-1)$. Pode-se dizer que essa seria uma comprovação evidente de atitudes ilegais de uso de informações confidenciais às empresas. 
Após mensurar a magnitude dos retornos anormais médios e dos retornos anormais médios cumulativos, é importante testar as hipóteses sobre o significado de tal cálculo. Assim, foi utilizado o tradicional teste $\mathrm{t}$, para o qual é necessário que os $\overline{A R}_{i t}$ sejam independentes e normalmente distribuídos. A estatística para a hipótese nula de que o retorno anormal médio do dia (t) é igual a zero e, de forma similar, de que os retornos anormais médios cumulativos entre 0 dia $\mathrm{t}_{1}$ e 0 dia $t_{2}$ - os quais representam o dia inicial e o dia final da janela do evento - são iguais a zero é determinada pelo teste da hipótese da Assimetria Informacional, de acordo com Garcia (2002, p. 18):

$$
t=\frac{\overline{A R}_{t}}{\sigma_{A A R_{t}} / \sqrt{n}}
$$

Em que:

$\sigma_{\mathrm{AAR}_{\mathrm{t}}}=$ estimativa do desvio padrão do retorno anormal médio no dia (t).

Para o teste da hipótese da eficiência semiforte do mercado, foi utilizada a estatística (t) para retornos acumulados, de acordo com MacKinlay (1997, p. 24):

$$
t=\frac{\overline{C A R}_{t_{1}, t_{2}}}{\sigma_{C A R_{t_{1}, t_{2}}} / \sqrt{n}}
$$

Em que:

$\sigma_{\mathrm{CARt}_{1}, \mathrm{t}_{2}}=$ desvio padrão dos retornos anormais cumulativos entre os dias $t_{1}$ et $_{2}$.

A aceitação ou rejeição das hipóteses pode ser observada na Figura 1.
Se Zcal $\notin$ (- Ztab; Ztab), rejeitamos $\mathrm{H}_{0}$ ao nível de significância $\alpha$.

$$
\begin{aligned}
& \text { Teste }(\mathrm{t}):\left\{\begin{array}{l}
H_{0} \Rightarrow \mu=\mu_{0} \\
H_{1} \Rightarrow \mu \neq \mu_{0}
\end{array}\right. \\
& t=\frac{\bar{X}-\mu_{0}}{\sigma / \sqrt{n}}
\end{aligned}
$$

Em que:

$$
\bar{X}=\text { média dos retornos } \bar{\mu}_{0} \text { é zero. }
$$

\section{APRESENTAÇÃO E DISCUSSÃO DOS RESULTADOS}

\section{Teste da assimetria informacional}

Para a anál ise da hi pótese central foram observados os retornos médios anormais para o dia zero dentro da janela de observação, ou seja, o dia da divulgação da convocação para assembléia (RCA ou AGO) em cuja pauta constasse a intenção de aumentar o capital via subscrição de ações ou do anúncio comunicando a intenção de aumentar o capital. Esse período conduziu à enumeração de 13 observações de cotações de 12 empresas distintas.

As hipóteses de interesse para os testes dos retornos anormais compreendem:

$\mathrm{H}_{0}$ : não é possível constatar a presença de retornos anormais depois do anúncio de subscrições $\left(\overline{A R}_{t}=0\right)$;

$\mathrm{H}_{1}$ : é possível constatar a presença de retornos anormais depois do anúncio de subscrições $\left(\overline{A R}_{t} \neq 0\right)$.

A média amostral e o desvio padrão dos retornos anormais para o dia zero foram cal culados com base nos 13 retornos anormais observados no dia zero (são 13 cotações consideradas na análise). A purados os 13 retornos

Figura 1 - Região crítica para os testes $\mathrm{H}=0$

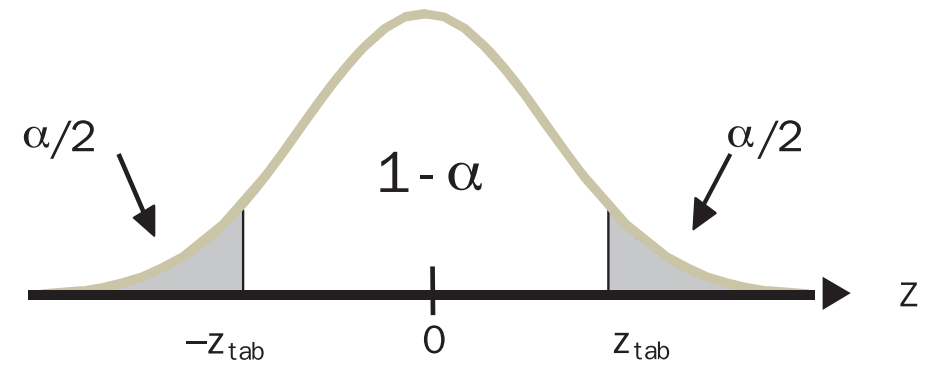

Fonte: Bussab e Morettin (2004, p. 333). 
anormais coletados, percebeu-se que a média amostral dos dados atingiu 0,012512, e o desvio padrão, 0,020148. Como o objetivo é verificar se os retornos médios anormais são iguais a zero ou não, utilizou-se o teste $t$ de Student para uma amostra. Para a aplicação do teste é necessário assumir que os retornos anormais são independentes e normal mente distribuídos. Para o dia zero, 0 teste $t$ foi realizado com base nos retornos anormais observados nas 13 cotações no dia zero. 0 t crítico, valor de referência para rejeição ou não da hipótese nula, foi igual a -2,2391. Logo, ao nível de significância de 5\%, pode-se rejeitar a hipótese nula (valor $p=0,045$ ), ou seja, é possível constatar a presença de retornos anormais no dia zero depois do anúncio de subscrições $\left(\overline{A R}_{i t} \neq 0\right)$.

\section{Teste para a eficiência semiforte do mercado}

As hipóteses de interesse que dizem respeito à eficiência semiforte do mercado são:

$\mathrm{H}_{0}$ : Não é possível constatar a presença de retornos anormais acumulados $\left(\overline{C A R}_{t_{1}, t_{2}}=0\right)$;

$\mathrm{H}_{1}$ : É possível constatar a presença de retornos anormais acumulados $\left(\overline{C A R}_{t_{1}, t_{2}} \neq 0\right)$.

0 procedimento utilizado para o teste das hipóteses - considerando como janela de evento o período (-20) a (-1) consistiu em calcular os retornos anormais médios de cada empresa no período considerado. Em seguida, calcularam-se os retornos anormais acumulados. A média amostral dos retornos acumulados no período de $(-20)$ a (-1) é-0,041552, e o desvio padrão, 0,017716. N esse caso, o t crítico encontrado foi de $-8,4563$ e, conseqüentemente, um valor-p de 0,000 , que leva à rejeição da hipótese nula. Dessa forma, é possível constatar a presença de retornos anormais acumulados no período $(-20)$ a $(-1)$ $\left(\overline{C A R}_{t, t, t} \neq 0\right)$, ao nível de significância de $5 \%$.

Os resultados para a janela 1 a 20 foram obtidos de maneira similar aos do período de $(-20)$ a $(-1)$. A média dos retornos anormais acumulados é -0,015495, e o desvio padrão, 0,011051. Ao nível de significância de 5\%, com t crítico de -5,0552, pode-se rejeitar a hipótese nula (valor- $p=0,000)$, ou seja, é possível constatar a presença de retornos anormais acumulados 20 dias após ao anúncio de subscrições $\left(\overline{C A R}_{t_{1}, t_{2}} \neq 0\right)$.

\section{CONSIDERAÇÕES FINAIS}

\section{Conclusões}

0 artigo procurou investigar, a partir da análise de even- tos no mercado de capitais brasileiro, se a divulgação de notícias convocando acionistas para AGO ou RCA, nas quais constasse em pauta a intenção de aumentar 0 capital ou mesmo 0 anúncio de emissões, influenciaria 0 preço das ações. A partir da pesquisa realizada, foram analisados 13 eventos, de 12 empresas distintas, no período compreendido entre 10 de julho de 1995 e 30 de abril de 2005, contemplando-se as empresas com emissões públicas que, neste período, atendiam aos requisitos de sel eção da amostra.

No que concerne ao teste de hipóteses ao qual as amostras da pesquisa foram submetidas, considerandose a premissa da ocorrência de retornos anormais após a divulgação de anúncios de subscrições, constatou-se que, conforme as expectativas iniciais do estudo, à luz da literatura pertinente, houve uma reação negativa dos preços das ações.

Percebeu-se a ocorrência de retornos anormais negativos significativos no dia zero, ou seja, no dia da veiculação do anúncio, com um nível de significância de 5\% nos testes realizados, sugerindo a existência de assimetria informacional no mercado. Desse modo, rejeitou-se a hipótese nula.

Em relação à análise dos retornos acumulados no período de $(-20)$ a $(-1)$, verificou-se que houve retornos em excesso diferentes de zero. Observou-se que os resultados encontrados na estatística t para os retornos anormais acumulados mostram a existência de reações antecipadas, o que pode indicar a presença de vazamento de informações.

No que concerne aos retornos acumulados no período de $(+1)$ a $(+20)$, concluiu-se que houve retornos em excesso diferentes de zero. Os resultados encontrados na estatística t para os retornos anormais acumulados mostram a existência de reações a posteriori. Foi possível constatar, em relação à função da existência de retornos anormais acumulados significativos, no período de $(-20)$ a $(-1)$ e $(+1)$ a $(+20)$, que a hipótese da eficiência semiforte do mercado pode ser rejeitada.

Dessa forma, em face dos resultados encontrados, este trabal ho sugere a existência de assimetria informacional no mercado de capitais brasileiro. Os resultados encontrados demonstram que os investidores reagem negativamente aos sinalizadores das emissões de novas ações. Assim, rejeitouse a hipótese nula, ou seja, é possível constatar a presença de retornos anormais depois do anúncio de subscrições.

Por fim, constatou-se a existência de retornos anormais, antecipados e posteriores, a novas emissões, rejeitando-se a hipótese da eficiência semiforte do mercado. É importante ressaltar que, conforme já preconizado por 


\section{ARTIGOS •ASSIMETRIA INFORMACIONAL E EFICIÊNCIA SEMIFORTE DO MERCADO}

Procianoy e Antunes (2001), a assimetria informacional é uma das principais causadoras dos desvios da eficiência de mercado, uma vez que na sua presença os preços das ações não refletem todas as informações rel evantes, sendo somente possível avaliar o fluxo de retorno da firma que é percebido pelo mercado.

Confrontados com as discussões estabelecidas anteriormente, os resultados encontrados mostraram-se consistentes com a base teórica utilizada. A existência de retornos anormais negativos, quando do anúncio de emissões, ratifica a hipótese de assimetria informacional, ou seja, os administradores possuem melhor informação sobre o valor da empresa do que os investidores externos. Os resultados encontrados neste trabal ho, desconsideradas as particularidades, vão ao encontro dos resultados de M yers e Majluf (1984), Miller e Rock (1985), Leal e Amaral (2000), Bertucci, Amaral e Garcia (2002) e Garcia (2002).

Este estudo diverge dos resultados encontrados por Garcia (2002) quanto à eficiência semiforte do mercado. Os retornos anormais negativos encontrados, antes e depois da emissão, não permitem a aceitação da eficiência do mercado na sua forma semiforte. Talvez essa divergência tenha sido ocasionada em função da amostra selecionada nos respectivos trabalhos. Enquanto Garcia (2002) utiliza emissões públicas, privadas e sem valor, este trabalho utiliza apenas emissões públicas. É importante que seja realizada uma investigação mais criteriosa, objetivando apurar esse ponto divergente.

\section{Limitações da pesquisa}

As principais limitações do estudo estão nos aspectos metodológicos específicos, ocasionados em função das particularidades do mercado brasileiro. Nesse sentido, aponta-se a ocorrência de um número limitado de eventos, característica do mercado local; a presença de forte concentração em poucos nomes; número reduzido de emissões de ações ordinárias, fazendo com que tenha sido necessário permitir a presença de ações ON ePN, as quais podem ter influenciado a mensuração dos retornos anormais, e o fato de que a teoria base do estudo desta pesquisa foi construída em contextos diferentes do brasileiro.

Final mente, registre-se a fragilidade deste diagnóstico no imenso universo de particulares do mercado brasileiro, o que leva a recomendar que não seja tomado como amostra definitiva. As conclusões aqui obtidas referem-se apenas às ações das empresas cadastradas na amostragem, de acordo com os critérios de sel eção estabelecidos e com o período de estudo. Assim, não se deve estender sua significância ao âmbito da generalização.

\section{NOTAS}

1 Significa a freqüência relativa de um tipo de evento numa longa seqüência de eventos.

2 Aleatoriedade implica a existência de igual probabilidade de os ativos estarem super ou subavaliados.

3 A distinção entre forma fraca e forma forte foi inicialmente proposta por Harry Roberts (1959).

$4 \mathrm{Na}$ verdade, o estudo de Akerlof vai muito além de simplesmente mostrar o que ocorre no mercado de veículos usados.

5 Este trabalho também parte desse pressuposto.

6 Este trabalho ratifica o de Myers e Majluf (1984), no sentido de que as empresas somente emitem novas ações se acreditarem que o seu preço está supervalorizado.

7 A listagem com a discriminação de todas as notícias divulgadas, compiladas do banco de dados da Consultoria Lafis, pode ser solicitada diretamente aos autores.

8 A variação do Ibovespa foi obtida no banco de dados da Consultoria Lafis.

9 As fórmulas apresentadas neste tópico foram obtidas de Cormelato e Terra (2003, p. 5-8) e MacKinlay (1997, p. 24).

10 Fórmula extraída de Mackinlay (1997, p. 24).

\section{REFERÊNCIAS}

AKERLOF, G. A. The market for lemons: quality uncertainty and the market mechanism. Quarterly Journal of Economics, v. 84, n. 3, p. 488-500, 1970.

BERTUCCI, L. A.; AMARAL, H. F.; GARCIA, F. G. A estratégia de financiamento com subscrições de ações: 0 caso de empresas brasileiras. In: ENCONTRO NACIONAL DA ASSOCIAÇÃO DOS CURSOS DE GRADUAÇÃO EM ADMINISTRAÇÃO, 13., 2002, Rio de Janeiro. Anais. Rio de Janeiro: Angrad, 2002.

BRIGHAM, E. F.; GAPENSHI, L. C.; EHRHARDT, M. C. Administração financeira: teoria e prática. Trad. Alexandre Loureiro Guimarães Alcântara e José Nicolas Albuja Salazar. Revisão técnica José Carlos Guimarães Alcântara. São Paulo: Atlas, 2001

BROWN, S. J.; WARNER, J. B. Measuring security price performance. Journal of Financial Economics, v. 8, n. 3, p. 205-258, 1980.

BUSSAB, W. O.; MORETIIN, P. A. Estatística básica. São Paulo: Saraiva, 2004

CORMELATO, G. M. B.; TERRA, P. R. S. Um estudo sobre a relevância das informações geradas nas apresentações das companhias abertas para a Associação 
Brasileira dos Analistas do Mercado de Capitais. In: EN CONTRO NACIONAL DE PROGRAMASDE PÓS-GRADUAÇÃO EM ADMINISTRAÇÃO, 19., 2003, Rio de Janeiro. Anais. Rio de Janeiro: AN PAD, 2203. p. 293-309.

COMISSÃO DE VALORES MOBILIÁRIOS. Disponível em বhttp://www. cvm.com.br>. Acessado em 27 mai. 2005.

DAM ODARAN, A. Avaliação de investimentos: ferramentas e técnicas para a determinação do valor de qualquer ativo. Rio de Janeiro: Qualitymark, 2002.

ELTON, E. J.; GRUBER, M. J. M odern portfolio theory and investment analysis. New York: John Whiley \& Sons Inc., 1995.

FAMA, E. F. The behavior of stock market prices. The Journal of Business, V. 38, n. 1, p. 34-105, 1965.

FAMA, E. F.; FISCHER, L.; JENSEN, M. C.; ROLL, R. The adjustment of stock prices to new information. International Economic Review, v. 10, $\mathrm{n}$. 1, p. 1-21, 1969.

FAMA, E. F. Efficient capital markets: a review of theory and empirical work. Journal of Finance, v. 25, n. 2, p. 383-417, 1970.

FAMA, Eugene F. Risk, return and equilibrium: empirical tests. Journal of Political Economy, n. 81, n. 3, p. 607-636, 1973.

FAMA, E. F. Efficient capital markets II. The Journal of Finance, v. 46, n. 5, p. 1575-1617, 1991.

FRENCH, K. R.; ROLL, R. Stock returns variances: the arrival of information and the reaction of trades. Journal of Financial Economics, v. 17, n. 1, p. 5-26, 1986.

GARCIA, F. G. Verificação da existência de assimetria de informações no processo de emissão de ações no mercado brasileiro: uma forma de medir a importância da estrutura de ativos da empresa. 2002. Tese (Doutorado em Administração de Empresas) - Escola de Administração de Empresas de São Paulo da Fundação Getúlio Vargas, São Paulo, 2002.

HERTZEL, M. et al. Long-run performance following private placements of equity. Journal of Finance, v. 57, n. 6, p. 2595-2617, 2002.
LAFISCONSULTORIA, ANÁLISESSETORIAISE DE EMPRESAS. Disponível em «http://www.lafis.com.br>. Acessado em 30 de mai. 2005.

LEAL, R. P. C.; AMARAL, A. S. Um momento para o insider trading: 0 período anterior ao anúncio de uma emissão pública de ações. In: LEAL, R. P. C.; COSTA JR., N. C. A.; LEM GRUBER, E. F. (Orgs.). Finanças corporativas. São Paulo: Atlas, 2000. p. 174-179. (Coleção Coppead de Administração).

MACKINLAY, A. C. Event studies in economics and finance. Journal of Economic Literature, v. 35, n. 1, p. 3-39, 1997.

MYERS, S. C. The capital structure puzzle. Journal of Finance, v. 39, n. 3, p. 575-592, 1984.

MYERS, S. C.; MAJLUF, N. Corporate financing and investment decision when firms have information that investors do not have. Journal of Financial Economics, v. 13, n. 2, p. 187-221, 1984.

PEROBELLI, F. F. C.; NESS JR., W. L. Reações do mercado acionário a variações inesperadas nos lucros das empresas: um estudo sobre a eficiência informacional no mercado brasileiro. In: ENCONTRO NACIONAL DE PROGRAMASDE PÓS-GRADUAÇÃO EM ADMINISTRAÇÃO, 24., 2000, Florianópolis (SC). Anais. Rio de Janeiro: AN PAD, 2000.

PROCIANOY, J. L.; ANTUNES, M. A. Os efeitos das decisões de investimento das firmas sobre os preços de suas ações no mercado de capitais. In: ENCONTRO NACIONAL DE PROGRAMAS DE PÓS-GRADUAÇÃO EM ADMINISTRAÇÃO, 25., 2001, Campinas. Anais. Rio de Janeiro: ANPAD, 2001.

ROBERTS, H. V. Statistical versus clinical prediction of the stock market. Unpublished work presented in the Conference of Securities Price Analysis. Chicago, 1967.

ROBERTS, H. V. Stock markets patterns and financial analysis: methodological suggestions. The Journal of Finance, v. 14, n. 1, p.1-10, 1959.

ROSS, S. A.; WESTERFIELD, R. W.; JAFFE, J. F. Administração financeira (corporate finance). São Paulo: Atlas, 1995.

\section{Artigo recebido em 22.11.2005. A provado em 11.06.2006.}

\section{Neuza Maria Belo}

Coordenadora do curso de Administração das Faculdades Pedro Leopoldo, professora convidada do MBA da Fundação Getulio Vargas e professora da Faculdade Pitágoras. M estrado profissional em Administração pelas

Faculdades Pedro Leopoldo.

Interesses de pesquisa nas áreas de mercado de capitais e finanças corporativas.

E-mail: nbelo@fgv.br

Endereço: Av. Flávio dos Santos, n. 320, apto 01, Bairro Floresta, Belo Horizonte - M G, 31015-150.

\section{Haroldo G uimarães Brasil}

Professor do Programa de M estrado Profissional em Administração das F aculdades Pedro Leopoldo eProfessor do IBMEC-M G. Doutor em Economia pela UFRJ.

Interesses de pesquisa nas áreas de finanças corporativas, gestão baseada em valor e precificação de ativos.

Email: strategor@uai.com.br

Endereço: Av. Lincoln Diogo Viana, 830, Dr. Lund, Pedro Leopoldo - MG, 33600-000. 